\title{
MR Imaging Features of the Cerebellum in Adult-Onset Neuronal Intranuclear Inclusion Disease: 8 Cases
}

\author{
(D) A. Sugiyama, (D) N. Sato, (D). Kimura, (D). Maekawa, (D) M. Enokizono, DY. Saito, DY. Takahashi, (D) H. Matsuda, and (D). Kuwabara
}

\begin{abstract}
SUMMARY: Neuronal intranuclear inclusion disease is a neurodegenerative disorder pathologically characterized by eosinophilic hyaline intranuclear inclusions. A high-intensity signal along the corticomedullary junction on DWI has been described as a specific MR imaging finding of the cerebrum in neuronal intranuclear inclusion disease. However, MR imaging findings of the cerebellum in neuronal intranuclear inclusion disease have not been fully evaluated. Here, we review MR imaging findings of the cerebellum in a series of 8 patients with pathologically confirmed neuronal intranuclear inclusion disease. The MR imaging results showed cerebellar atrophy (8/8 patients) and high-intensity signal on FLAIR images in the medial part of the cerebellar hemisphere right beside the vermis (the "paravermal area") (6/8) and in the middle cerebellar peduncle (4/8). The paravermal abnormal signals had a characteristic distribution, and they could be an indicator of the diagnosis of neuronal intranuclear inclusion disease even when using the results of past MR imaging examinations in which DWI findings were not examined.
\end{abstract}

ABBREVIATIONS: FAB = Frontal Assessment Battery; FXTAS = fragile X-associated tremor/ataxia syndrome; MMSE = Mini-Mental State Examination; NIID = neuronal intranuclear inclusion disease

$\mathbf{N}$ euronal intranuclear inclusion disease (NIID) is a neurodegenerative disorder pathologically characterized by eosinophilic hyaline intranuclear inclusions in the central and peripheral nervous systems and in the visceral organs. ${ }^{1}$ Both sporadic and familial cases of NIID are reported, and NIID is divided into 3 clinical subgroups according to the individual's age at onset and disease duration: the infantile, juvenile, and adult forms. ${ }^{2}$ The highly variable clinical manifestations of NIID previously made the antemortem diagnosis difficult, but since the usefulness of a skin biopsy for the diagnosis was described in sporadic ${ }^{3}$ and familial cases of NIID, ${ }^{4}$ the number of NIID diagnoses has increased.

Some researchers also noted that an NIID finding on brain MR imaging (ie, a high-intensity signal along the corticomedullary junction on DWI) is a strong indicator of the antemortem diagnosis of NIID. ${ }^{3,5}$ However, the MR imaging findings of the cerebellum in patients with NIID have not been fully evaluated, to our

Received February 22, 2017; accepted after revision May 20.

From the Departments of Radiology (A.S., N.S., Y.K., T.M., M.E.), Pathology and Laboratory Medicine (Y.S.), Neurology (Y.T.), and Integrative Brain Imaging Center (H.M.), National Center of Neurology and Psychiatry, Tokyo, Japan; and Department of Neurology (A.S., S.K.), Graduate School of Medicine, Chiba University, Chiba, Japan.

Please address correspondence to Noriko Sato, MD, Department of Radiology, National Center of Neurology and Psychiatry, 4-1-1 Ogawa-Higashi, Kodaira, Tokyo 187-0031, Japan; e-mail: snoriko@ncnp.go.jp

http://dx.doi.org/10.3174/ajnr.A5336 knowledge. We recently encountered patients in whom abnormal signals were distributed in characteristic regions of the cerebellum on brain MR images. Herein, we present these MR imaging findings, focusing on the cerebellum in 8 patients with adult-onset NIID.

\section{Case Series}

This retrospective study was approved by our institutional review board. The diagnosis of NIID was made histopathologically by skin biopsy in all cases. We reviewed the medical records of the 8 patients including their medical history and neurologic examination findings, Mini-Mental State Examination (MMSE), Frontal Assessment Battery (FAB), and CSF results. A score of 24 was used as the cutoff for the MMSE, ${ }^{6}$ and the published age-matched average was used as the cutoff for the FAB. ${ }^{7,8}$ All MR imaging examinations were performed as routine clinical care with $1.5 \mathrm{~T}$ in 3 patients and $3 \mathrm{~T}$ in the other 5 patients. Diffusion-weighted and FLAIR images were available for all patients. The MR imaging data of each patient were retrospectively evaluated separately and then jointly by 2 neuroradiologists (Y.K. and M.E.).

We evaluated the following findings: 1) high-intensity signal along the corticomedullary junction on DWI, 2) diffuse high-intensity signal of cerebral white matter on FLAIR images, 3) atrophy of the cerebellum, 4) high-intensity signal in the medial part of the cerebellar hemisphere right beside the vermis (the "paravermal area") on FLAIR images (Fig 1), and 
5) high-intensity signal in the middle cerebellar peduncle on FLAIR images (Fig 1B).

In all 8 cases, NIID was suspected from cerebral DWI findings, and a skin biopsy was performed. Light microscopy showed eosinophilic ubiquitin-positive and p62-positive intranuclear inclusions in the adipocytes, fibroblasts, and sweat gland cells. Electron microscopy was conducted in all patients except patient 6 , and it revealed attenuated filament material without a limiting
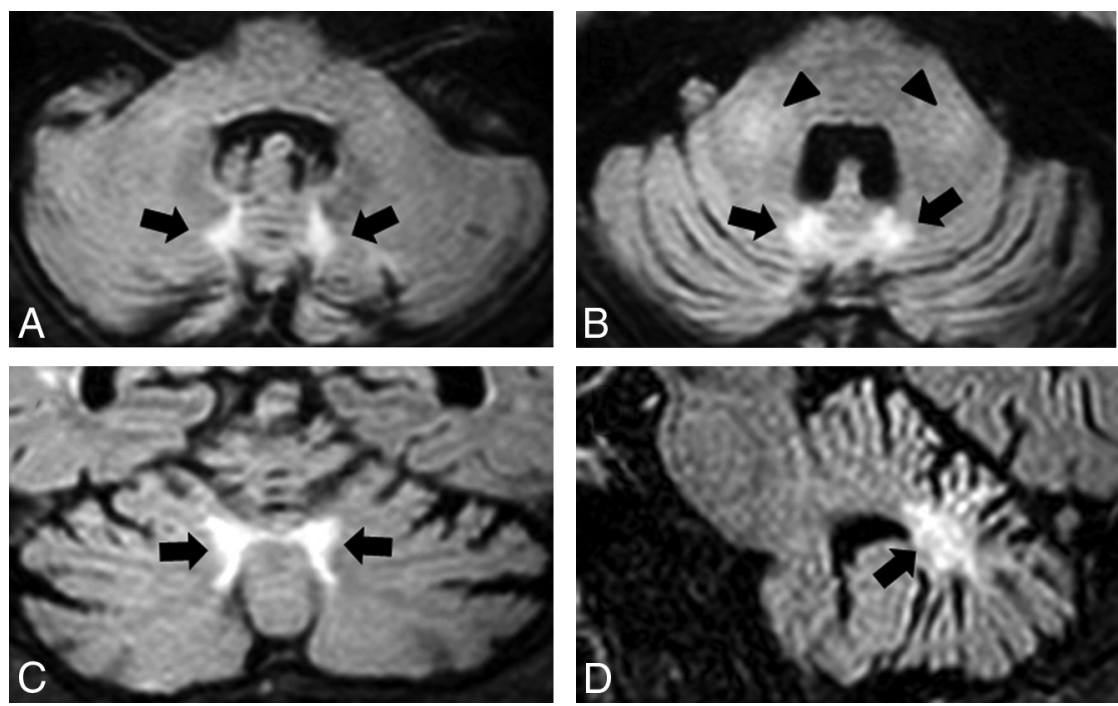

FIG 1. A representative case (patient 1 ) showing the abnormal signals at the paravermal area and the middle cerebellar peduncle. FLAIR axial images ( $A$ and $B$ ), a coronal image $(C)$, and a sagittal image $(D)$ show atrophy of the cerebellum and bilateral high signal intensity in the medial part of the cerebellar hemisphere immediately beside the vermis (the paravermal area) (black arrows) and in the middle cerebellar peduncle (black arrowheads). membrane. The patients' clinical presentations are summarized in Table 1.

Dementia was observed in 3 of the 8 patients $(37.5 \%)$. Mild ataxia was found in 3 patients $(37.5 \%)$. In all cases, the deep tendon reflex was reduced or absent. One of the 8 patients showed a decreased MMSE score, and 5 of the 7 patients showed impaired FAB scores.

The CSF examinations showed elevated protein in all cases. The MR imaging findings of the 8 patients with NIID are summarized in Table 2. MR imaging showed a high-intensity signal along the corticomedullary junction on DWI and diffuse high-intensity signal of cerebral white matter and cerebellar atrophy on FLAIR images in all cases (Fig 2). Six patients (75\%) showed abnormal FLAIR high-intensity signal in the paravermal area (Figs 1 and 2 ). Four patients (50\%) showed high-intensity signal in the middle cerebellar peduncle (Figs 1 and 3).

\section{DISCUSSION}

We have presented the MR imaging features of the cerebellum in 8 patients with pathologically confirmed adult-onset NIID. We observed abnormal FLAIR high-intensity signal in the paravermal area and middle cerebellar peduncle as characteristic MR imaging findings of

Table 1: Summary of the clinical features of patients with NIID

\begin{tabular}{|c|c|c|c|c|c|c|c|c|}
\hline & \multicolumn{8}{|c|}{ Patient No. } \\
\hline & 1 & 2 & 3 & 4 & 5 & 6 & 7 & 8 \\
\hline Age at onset (yr) & 64 & 52 & 62 & 62 & 67 & 67 & 67 & 64 \\
\hline Sex & M & $\mathrm{F}$ & $\mathrm{F}$ & $M$ & $\mathrm{~F}$ & M & $\mathrm{F}$ & M \\
\hline Disease duration at MRI (yr) & 2 & 9 & 8 & 3 & 5 & 6 & 1 & 5 \\
\hline \multicolumn{9}{|l|}{ Clinical manifestations } \\
\hline Dementia & - & - & - & + & + & - & + & - \\
\hline Delusion & - & - & + & - & - & - & - & - \\
\hline Muscle weakness & - & - & - & - & - & - & - & - \\
\hline Tremor & - & - & Postural & - & Postural & Postural & - & Resting, postura \\
\hline Rigidity & - & - & - & - & - & - & - & - \\
\hline Ataxia & - & - & - & + & + & - & - & + \\
\hline Hyporeflexia or areflexia in DTR & + & + & + & + & + & + & + & + \\
\hline Sensory disturbance & - & - & - & - & - & - & - & - \\
\hline Urinary incontinence & - & - & - & + & + & - & - & - \\
\hline Transient visual field abnormality & + & + & - & - & - & - & - & + \\
\hline Transient hemiparesis & - & + & - & - & - & - & - & - \\
\hline Transient abnormal behavior & - & + & - & + & - & + & - & - \\
\hline Generalized convulsion & - & - & - & - & - & - & - & - \\
\hline Disturbance of consciousness & - & - & - & - & - & + & + & + \\
\hline \multicolumn{9}{|l|}{ Cognitive screening test } \\
\hline MMSE & 30 & 29 & 30 & $14^{\mathrm{a}}$ & 30 & 28 & 24 & 29 \\
\hline \multicolumn{9}{|l|}{ Frontal lobe function test } \\
\hline$F A B$ & $13^{b}$ & 16 & $14^{\mathrm{b}}$ & $11^{\mathrm{b}}$ & $12^{\mathrm{b}}$ & 16 & $8^{\mathrm{b}}$ & NE \\
\hline \multicolumn{9}{|l|}{ CSF } \\
\hline Cell $\left(\mathrm{mm}^{3}\right)$ & 3 & 2 & 4 & 1 & 1 & 6 & $\mathrm{NE}$ & $\mathrm{NE}$ \\
\hline Protein $(\mathrm{mg} / \mathrm{dL})$ & 66 & 55 & 100 & 47 & 52 & 48 & $\mathrm{NE}$ & NE \\
\hline
\end{tabular}

Note:-DTR indicates deep tendon reflex; -, absence of the manifestation; +, presence of the manifestation; NE, not examined

a Decreased MMSE score below a cutoff score of 24.

${ }^{\mathrm{b}}$ Decreased FAB score below the published age-matched average. 


\begin{tabular}{|c|c|c|c|c|c|c|c|c|}
\hline & \multicolumn{8}{|c|}{ Patient No. } \\
\hline & 1 & 2 & 3 & 4 & 5 & 6 & 7 & 8 \\
\hline \multicolumn{9}{|l|}{ Cerebrum } \\
\hline High-intensity signal along the corticomedullary junction on DWI & + & + & + & + & + & + & + & + \\
\hline Diffuse high-intensity signal of cerebral white matter on FLAIR images & + & + & + & + & + & + & + & + \\
\hline \multicolumn{9}{|l|}{ Cerebellum } \\
\hline Atrophy & + & + & + & + & + & + & + & + \\
\hline $\begin{array}{l}\text { High-intensity signal in the medial part of cerebellar hemisphere right beside } \\
\text { the vermis on FLAIR images }\end{array}$ & + & - & + & + & + & + & - & + \\
\hline High-intensity signal in the middle cerebellar peduncle on FLAIR images & + & + & + & - & - & + & - & - \\
\hline
\end{tabular}

Note:- - indicates absence of the finding; + , presence of the finding.
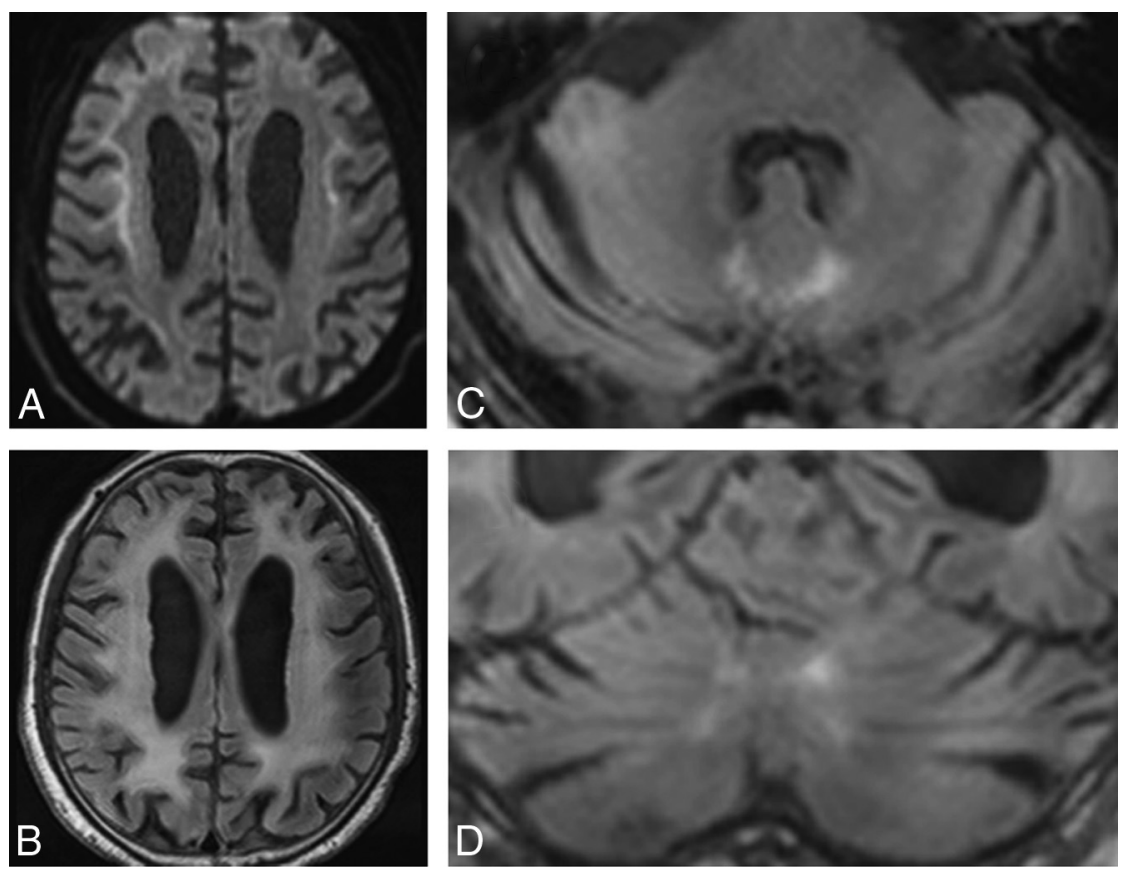

FIG 2. Patient 4. DWI (A) shows high-intensity signal along the corticomedullary junction. A FLAIR axial image $(B)$ shows diffuse high intensity in the bilateral cerebral hemispheres. FLAIR axial $(C)$ and coronal $(D)$ images show atrophy of the cerebellum and high-intensity signal in the medial part of the cerebellar hemisphere right beside the vermis (the paravermal area).

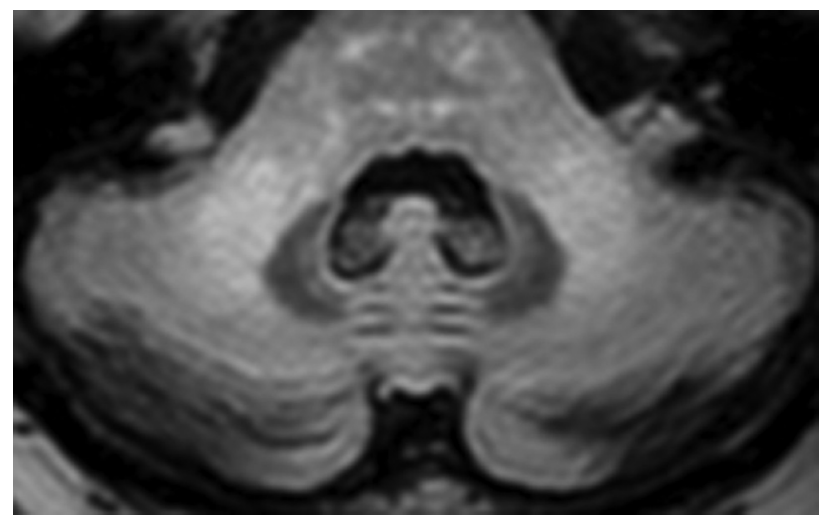

FIG 3. Patient 2. A FLAIR axial image shows bilateral high signal intensities in the middle cerebellar peduncle.

the cerebellum in NIID. Although cerebellar atrophy in NIID has been described in several cases, ${ }^{3,9,10}$ there is no report focusing on the distribution of abnormal signals in the cerebellum.

Previous studies have demonstrated that remarkable diffuse high-intensity signal of the cerebral white matter and DWI high- intensity signal along the corticomedullary junction are characteristic MR imaging findings of patients with NIID., The DWI finding of high-intensity signal along the corticomedullary junction could thus be a strong indicator of the diagnosis of NIID. According to a study comparing MR imaging and pathologic findings in NIID, DWI high-intensity signal along the corticomedullary junction and FLAIR high-intensity signal in the white matter correlated with pathologic spongiotic changes and diffuse myelin pallor without spongiosis, respectively. ${ }^{11}$ The spongiotic changes were restricted to the subcortical lesions proximal to the $\mathrm{U}$-fibers, and these changes might induce an inactivation of water diffusion.

That report ${ }^{11}$ also described a remarkable loss of glial fibrillary acidic protein-positive astrocytes compared with relatively mild axonal loss in the subcortical lesions, and astrocyte dysfunction has been considered a possible cause of white matter damage that ranges from myelin pallor to spongiotic change. These MR imaging findings extend predominantly into the frontal lobe and are thought to be related to white matter dementia, which is more easily detectable by the FAB than the MMSE. ${ }^{5}$ Consistent with this previously reported finding, most of our patients showed a decreased FAB score. Although it was not observed in our patients, transient focal brain edema with gadolinium enhancement has also been reported in patients with NIID during subacute encephalic episodes. ${ }^{5}$

In accordance with previous reports, ${ }^{3,9,10}$ all 8 of our patients with NIID presented with cerebellar atrophy. In addition, an abnormal signal in the medial part of the cerebellar hemisphere right beside the vermis, which we defined as the paravermal area, was observed at a high frequency in our patient series. The paravermal area is included in the intermediate part of the cerebellar hemisphere that receives somatosensory input from the limbs and projects via the interposed nucleus to the lateral corticospinal and rubrospinal systems. ${ }^{12}$ A previous investigation revealed that lesions in this intermediate part induced impaired gait balance control. ${ }^{13}$

In the present study, the relationship between the extent of the lesion and the severity of ataxia could not be assessed, but all 3 
patients with ataxia presented with an abnormal signal in the paravermal area. It is possible that the lesions in the paravermal area observed in our patients influence the ataxic gait in NIID. In our patients, the second most frequent abnormal signal in the cerebellum was the middle cerebellar peduncle lesion. Although we could not determine the pathologic background of these abnormal signals in the cerebellum in our patients, in previous reports describing the cerebellar pathology of NIID, a loss of myelin in the white matter of the cerebellum was described.9,14,15

The paravermal abnormal signal observed in our patients might be a specific finding for NIID. Another lesion in the medial part of the cerebellar hemisphere, in the peridentate white matter with and without a middle cerebellar peduncle lesion, has been described in several disorders, such as fragile $\mathrm{X}$-associated tremor/ataxia syndrome (FXTAS), ${ }^{16,17}$ Erdheim-Chester disease, ${ }^{18}$ neurofibromatosis, ${ }^{19}$ and progressive multifocal leukoencephalopathy. ${ }^{20}$ However, the distribution of the lesions in the peridentate white matter observed in these disorders is different from that in the lesions in the paravermal area found in our cases. Although the term "paravermal" has been used in a case with brain infarction, ${ }^{21}$ it has never been used to describe a lesion of a neurodegenerative disorder, to our knowledge.

The paravermal abnormal signal observed in our patients has a unique distribution, and it could be an indicator of the diagnosis of NIID, along with the DWI finding of a high-intensity signal along the corticomedullary junction. The middle cerebellar peduncle lesion is also considered a characteristic finding of NIID, though it can be found in other neurodegenerative disorders such as FXTAS, multiple system atrophy, and spinocerebellar ataxia and diseases due to other etiologies (neoplasm, metabolic, cerebrovascular, inflammatory, and demyelinating diseases). ${ }^{22}$ Like the high-intensity signal along the corticomedullary junction on DWI, this lesion may also help clinicians distinguish between NIID and clinically similar diseases such as gelsolin amyloidosis, which can present with neuropathy, ataxia, and dementia. ${ }^{23}$

The limitation of this study was that in no patients was brain pathology obtained. However, in both sporadic and familial cases of NIID, it was reported that nuclear inclusions detected by skin biopsy are morphologically and immunohistochemically identical to those reported for NIID inclusions in neuronal cells. ${ }^{3,4}$ Moreover, in cases of NIID diagnosed by both postmortem dissection and skin biopsy, the histopathologic features of the inclusions in the skin and central nervous system tissues were identical. ${ }^{5}$ We therefore think that the absence of postmortem cases of NIID does not limit the validity of our findings. On the other hand, as in our patients, a skin biopsy has been performed, with the abnormal findings on DWI as a trigger for most cases reported in recent years. ${ }^{5}$ The frequency of an abnormal signal along the corticomedullary junction on DWI may be overestimated in NIID.

Another limitation of our study is that the CGG repeat length of the FMR1 gene was not analyzed. In FXTAS, which is caused by permutation alleles of the FMR1 gene, eosinophilic ubiquitinpositive intranuclear inclusions, similar to those reported in NIID, were observed in neurons and glial cells. ${ }^{24,25}$ However, whereas the core clinical features of FXTAS are progressive tremor and gait ataxia, the core clinical feature of adult-onset
NIID in our patients was dementia. ${ }^{5,26}$ There was no family history of symptoms or medical history that suggested FXTAS in any of our patients. In addition, in a study of 27 cases of NIID with the analyzed FMR1 gene, all cases showed a normal range of CGG repeats. ${ }^{5}$ The possibility that FXTAS was present among our patients thus seems to be extremely low.

\section{CONCLUSIONS}

We observed abnormal FLAIR high-intensity signals in the paravermal area and middle cerebellar peduncle other than cerebellar atrophy as characteristic MR imaging findings of the cerebellum in NIID. The paravermal abnormal signal could indicate the diagnosis of NIID, even when using the findings of past MR imaging examinations in which DWI was not performed.

Disclosures: Satoshi Kuwabara—UNRELATED: Board Membership: Journal of Neurology, Neurosurgery, and Psychiatry, Comments: I serve as Deputy Editor of the journal; Other: Japanese Agency of Medical Research Development, Comments: grant for intractable neuroimmunologic disease. ${ }^{*}$ Money paid to the institution.

\section{REFERENCES}

1. Lindenberg R, Rubinstein LJ, Herman MM, et al. A light and electron microscopy study of an unusual widespread nuclear inclusion body disease: a possible residuum of an old herpesvirus infection. Acta Neuropathol 1968;10:54-73 CrossRef Medline

2. Takahashi-Fujigasaki J. Neuronal intranuclear hyaline inclusion disease. Neuropathology 2003;23:351-59 CrossRef Medline

3. Sone J, Kitagawa N, Sugawara E, et al. Neuronal intranuclear inclusion disease cases with leukoencephalopathy diagnosed via skin biopsy. J Neurol Neurosurg Psychiatry 2014;85:354-56 CrossRef Medline

4. Sone J, Tanaka F, Koike H, et al. Skin biopsy is useful for the antemortem diagnosis of neuronal intranuclear inclusion disease. $\mathrm{Neu}$ rology 2011;76:1372-76 CrossRef Medline

5. Sone J, Mori K, Inagaki T, et al. Clinicopathological features of adult-onset neuronal intranuclear inclusion disease. Brain 2016; 139:3170-86 CrossRef Medline

6. Wind AW, Schellevis FG, Van Staveren G, et al. Limitations of the Mini-Mental State Examination in diagnosing dementia in general practice. Int J Geriatr Psychiatry 1997;12:101-08 Medline

7. Dubois B, Slachevsky A, Litvan I, et al. The FAB: a Frontal Assessment Battery at bedside. Neurology 2000;55:1621-26 CrossRef Medline

8. Appollonio I, Leone M, Isella V, et al. The Frontal Assessment Battery (FAB): normative values in an Italian population sample. $\mathrm{Neu}$ rol Sci 2005;26:108-16 CrossRef Medline

9. Sloane AE, Becker LE, Ang LC, et al. Neuronal intranuclear hyaline inclusion disease with progressive cerebellar ataxia. Pediatr Neurol 1994;10:61-66 CrossRef Medline

10. Zannolli R, Gilman S, Rossi S, et al. Hereditary neuronal intranuclear inclusion disease with autonomic failure and cerebellar degeneration. Arch Neurol 2002;59:1319-26 CrossRef Medline

11. Yokoi S, Yasui K, Hasegawa Y, et al. Pathological background of subcortical hyperintensities on diffusion-weighted images in a case of neuronal intranuclear inclusion disease. Clin Neuropathol 2016; 35:375-80 CrossRef Medline

12. Kandel ER, Schwartz JH, Jessell TM, et al. Principles of Neural Science. 5th ed. New York: McGraw-Hill; 2013:960-81

13. Ilg W, Giese MA, Gizewski ER, et al. The influence of focal cerebellar lesions on the control and adaptation of gait. Brain 2008;131: 2913-27 CrossRef Medline

14. Soffer D. Neuronal intranuclear hyaline inclusion disease presenting as Friedreich's ataxia. Acta Neuropathol 1985;65:322-29 CrossRef Medline

15. Funata N, Maeda Y, Koike M, et al. Neuronal intranuclear hyaline inclusion disease: report of a case and review of the literature. Clin Neuropathol 1990;9:89-96 Medline 
16. Brunberg JA, Jacquemont S, Hagerman RJ, et al. Fragile $\mathrm{X}$ permutation carriers: characteristic MR imaging findings of adult male patients with progressive cerebellar and cognitive dysfunction. AJNR Am J Neuroradiol 2002;23:1757-66 Medline

17. Jacquemont S, Hagerman RJ, Leehey M, et al. Fragile X permutation tremor/ataxia syndrome: molecular, clinical, and neuroimaging correlates. Am J Hum Genet 2003;72:869-78 CrossRef Medline

18. Weidauer S, von Stuckrad-Barre S, Dettmann E, et al. Cerebral Erdheim-Chester disease: case report and review of the literature. $\mathrm{Neu}$ roradiology 2003;45:241-45 CrossRef Medline

19. Menor F, Marti-Bonmati L, Arana E, et al. Neurofibromatosis type 1 in children: MR imaging and follow-up studies of central nervous system findings. Eur J Radiol 1998;26:121-31 CrossRef Medline

20. Boster A, Hrena S, Berger JR, et al. Progressive multifocal leukoencephalopathy and relapsing-remitting multiple sclerosis: a comparative study. Arch Neurol 2009;66:593-99 Medline

21. Amarenco P, Chevrie-Muller C, Roullet E, et al. Paravermal infarct and isolated cerebellar dysarthria. Ann Neurol 1991;30:211-13 CrossRef Medline

22. Okamoto K, Tokiguchi S, Furusawa T, et al. MR features of diseases involving bilateral middle cerebellar peduncles. AJNR Am J Neuroradiol 2003;24:1946-54 Medline

23. Pihlamaa T, Suominen S, Kiuru-Enari S. Familial amyloidotic polyneuropathy type IV-gelsolin amyloidosis. Amyloid 2012;19:30-33 CrossRef Medline

24. Greco CM, Berman RF, Martin RM, et al. Neuropathology of fragile $\mathrm{X}$-associated tremor/ataxia syndrome (FXTAS). Brain 2006;129: 243-55 Medline

25. Gokden M, Al-Hinti JT, Harik SI. Peripheral nervous system pathology in fragile X tremor/ataxia syndrome (FXTAS). Neuropathology 2009;29:280-84 CrossRef Medline

26. Hagerman RJ, Leehey M, Heinrichs W, et al. Intention tremor, parkinsonism, and generalized brain atrophy in male carriers of fragile X. Neurology 2001;57:127-30 CrossRef Medline 